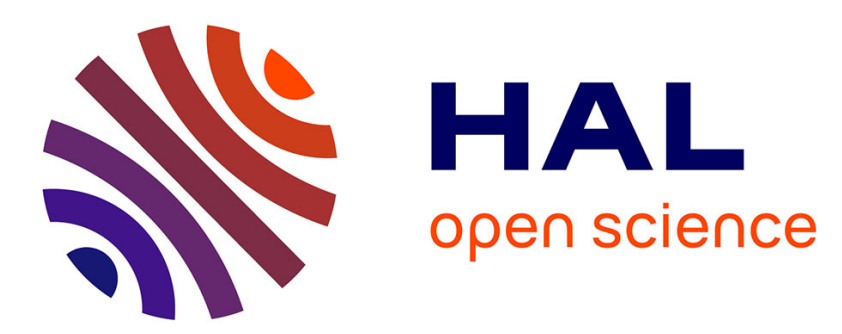

\title{
Effects of small particles on the mechanical behavior and on the local damage of highly filled elastomers
}

\author{
Paul-Aymé Toulemonde, Julie Diani, Pierre Gilormini, Nancy Desgardin, \\ Robert Nevière
}

\section{- To cite this version:}

Paul-Aymé Toulemonde, Julie Diani, Pierre Gilormini, Nancy Desgardin, Robert Nevière. Effects of small particles on the mechanical behavior and on the local damage of highly filled elastomers. Journal of Materials Science, 2017, 52 (2), pp.878-888. 10.1007/s10853-016-0383-9 . hal-01403265

\section{HAL Id: hal-01403265 \\ https://hal.science/hal-01403265}

Submitted on 25 Nov 2016

HAL is a multi-disciplinary open access archive for the deposit and dissemination of scientific research documents, whether they are published or not. The documents may come from teaching and research institutions in France or abroad, or from public or private research centers.
L'archive ouverte pluridisciplinaire HAL, est destinée au dépôt et à la diffusion de documents scientifiques de niveau recherche, publiés ou non, émanant des établissements d'enseignement et de recherche français ou étrangers, des laboratoires publics ou privés. 


\title{
Effects of small particles on the mechanical behavior and on the local damage of highly filled elastomers
}

\author{
Paul-Aymé Toulemonde • Julie Diani . \\ Pierre Gilormini · Nancy Desgardin · Robert \\ Nevière
}

\begin{abstract}
The mechanical behavior and damage of highly filled elastomers such as propellants is studied experimentally. A model material made of a polyacrylate matrix filled with glass beads and energetic binders filled with ammonium perchlorate and HMX have been formulated. The focus is on materials containing micrometric size particles. The size of fillers was varied from a few microns to hundreds of microns in order to study the impact of the size of particles. The materials stress-strain responses and the volume changes during uniaxial tensile tests have been recorded. Microtomographic slices of strained samples have been obtained in order to look at the type of damage sustained by the acrylate/glass bead materials. It appears that in the presence of large particles, composites showing early prominent crack benefits from the addition of small particles, whereas composites showing well dispersed matrix/particle decohesion without large cracks show no change of behavior when small particles are added.
\end{abstract}

Keywords Particulate composite $\cdot$ Elastomer $\cdot$ Size effect $\cdot$ Debonding $\cdot$ Cracking · Dilatation

P.-A. Toulemonde (corresp. author)

Laboratoire PIMM, ENSAM, CNRS, CNAM, 151 bd de l'Hôpital, 75013 Paris, France

Herakles groupe Safran, Centre de recherche du Bouchet, 9 rue Lavoisier, 91710 Vert-le-Petit, France

E-mail: patoulemonde@gmail.com

Tel: +33682298251

J.Diani

LMS, Ecole Polytechnique, CNRS, Université Paris-Saclay, 91128 Palaiseau, France

E-mail: julie.diani@gmail.com

P. Gilormini

Laboratoire PIMM, ENSAM, CNRS, CNAM, 151 bd de l'Hôpital, 75013 Paris, France

E-mail: pierre.gilormini@ensam.eu

N. Desgardin and R. Nevière

Herakles groupe Safran, Centre de recherche du Bouchet, 9 rue Lavoisier, 91710 Vert-le-Petit, France

E-mail: nancy.desgardin@herakles.com; robert.neviere@herakles.com 


\section{Introduction}

Solid propellants consist in an elastomer matrix filled with a high volume fraction (up to $90 \mathrm{wt} \%$ ) of energetic particles, which size lies in the range 0 to $200 \mu \mathrm{m}$ [9]. Their first function is to deliver enough thrust to extract rockets from the Earth field of gravity. To maximize the provided power, propellants are commonly castbonded to the wall of the rocket [4], which creates zones loaded in tension. Solid propellants stiffness and failure properties in tension must fulfill stringent design constraints.

The high volume fraction of particles [31], the nonlinear hyperelastic behavior of the elastomer matrix, the particle size $[5,10,14,31]$ and the matrix/particles adhesion $[11,14,15]$ give very specific tensile properties to solid propellants compared to other class of filled polymer matrix. For instance, it has been showed that damage by filler/matrix debonding has a very significant effect on the mechanical behavior of solid propellants $[20,3,1,26]$ that is not fully understood despite recent studies [28, 29].

The particle size impacts the combustion properties [22] and the material processability [27]. It was also recognized that filling the propellant with small particles is beneficial to the mechanical properties [14, 31, 28]. This feature is consistent with the size effect observed on explosive materials [24,6] loaded in compression and on a broader range of particulate polymer composites $[2,8]$ loaded in tension. For the latter composites, adding small particles has no impact on the initial Young modulus but increases the material strength [2]. It is thus tempting to mix large and small particles in propellants to achieve targeted mechanical behavior and failure properties. However, to this day, very few data are available on the effect of mixing large and small particles on the mechanical behavior of highly filled elastomers. Studies have been recently conducted on explosive materials loaded in compression at low and high strain rates [6]. In that contribution, the authors have emphasized that the mechanical behavior of explosives with bimodal size distributions is distinct from the mechanical behavior of both large particles and small particles only composites.

The present work offers an experimental study, focusing on the effect of adding small particles on the mechanical behavior of highly filled elastomers at low strain rate. A close look is taken at the damage mechanisms: matrix/particle debonding and crack appearance. For that purpose, the material stress-strain response and dilatation are measured during uniaxial tension tests. Moreover, microtomographic slices of strained samples are recorded. In what follows, the materials and experimental techniques are first described, then results on polyacrylate/glass beads composites and on propellants are presented and discussed.

\section{Experimental section}

\subsection{Materials}

As mentioned above, two types of materials are produced and tested in the present study: (i) highly filled elastomers made of glass beads surrounded by a polyacrylate matrix and (ii) energetic binders filled with either ammonium perchlorate or HMX. 


\subsubsection{Polyacrylate and glass beads}

Polyacrylate networks are easily tailorable [23]. A mix based on 98.8 mol\% methylacrylate crosslinked with $1.2 \mathrm{~mol} \%$ poly(ethylene glycol) dimethacrylate, whose molecular mass is 750 g. $\mathrm{mol}^{-1}$, was used for the polyacrylate composites. It was copolymerized thanks to $0.2 \mathrm{~mol} \%$ 2,2-dimethoxy-2-phenylacetophenone in a CL1000 UV chamber during 55 minutes. The reactant were purchased from SigmaAldrich and used as received. DMA temperature sweep run at $1 \mathrm{~Hz}$ on the polyacrylate exhibits a loss modulus peak at $8^{\circ} \mathrm{C}$. Therefore, the material stands in the rubbery state when tested at small strain rate at room temperature.

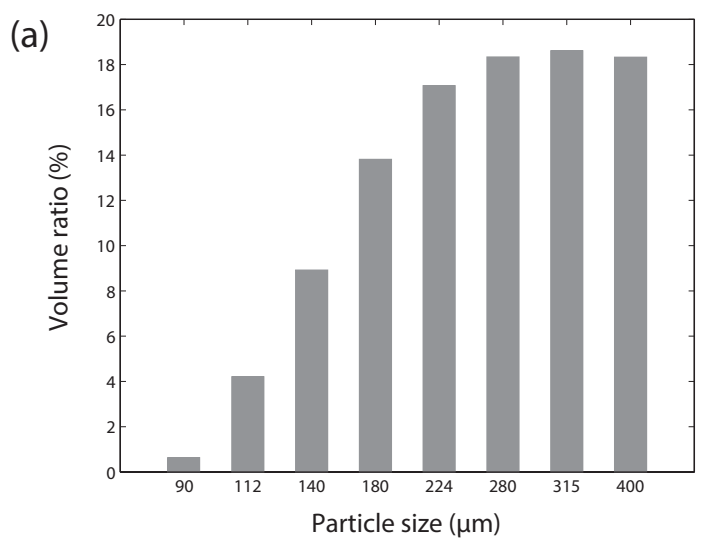

(b)

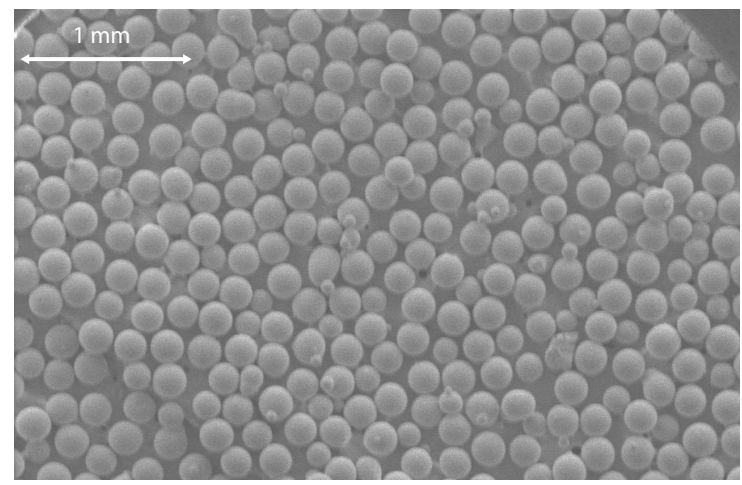

Fig. 1 (a) Size distribution and (b) shape of the large glass beads.

As regards the glass beads, two size distributions were obtained by sieving silica glass beads purchased from ARENA. The small particles have a size within the interval $80-90 \mu \mathrm{m}$. The large particles have the size distribution presented in figure 1a and their average size is $265 \mu \mathrm{m}$. The shape of the glass beads is mostly round as Figure $1 \mathrm{~b}$ shows.

The composites were produced by: (i) pouring the uncrosslinked polyacrylate network in a mold consisting in two parallel vertical plates separated by an interspace, and then (ii) adding the glass beads into the mold. The beads packed by gravity. When several sizes of particles were used, the particles were first mixed be- 
(a)

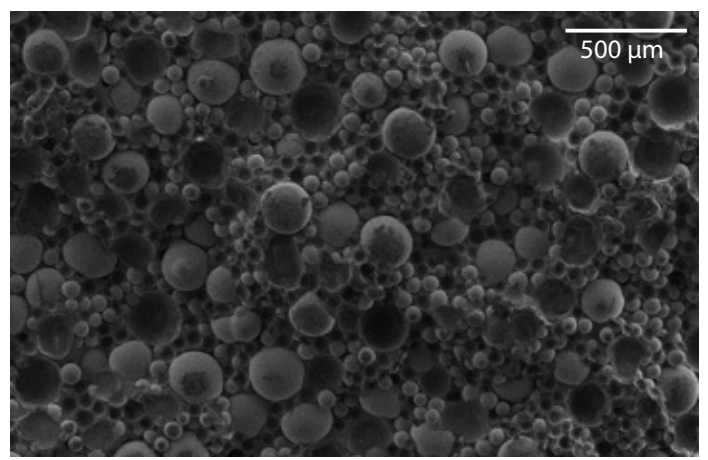

(b)

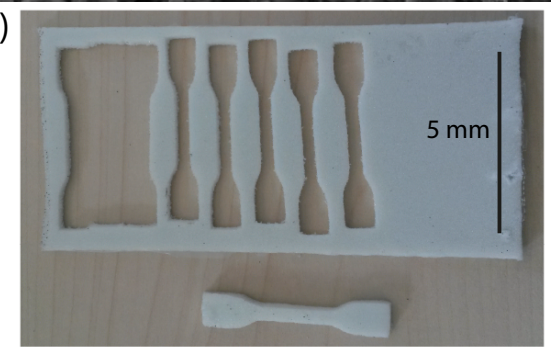

Fig. 2 (a) SEM image of the bidisperse material and (b) photograph of polyacrylate/glass beads samples for uniaxial tensile test.

fore being added to the polymer matrix. Figure 2a illustrates how large and small beads are well dispersed in bidisperse materials. Dogbone samples were punched into the composite plates. As figure $2 \mathrm{~b}$ shows, the samples loading direction is orthogonal to the direction of packing. The density of each sample was measured with a XS203S Mettler-Toledo densitometer. Samples containing small beads or large beads only reached a maximum volume fraction of particles of $55 \%$. For bidisperse materials, the wide particles size distribution promotes better packing [9], and a volume fraction of $60 \%$ was achieved consistently.

Table 1 Content of the polyacrylate/glass beads composites used in the present study

\begin{tabular}{llll}
\hline Name & $\begin{array}{c}\text { Small particles } \\
\text { volume fraction }\end{array}$ & $\begin{array}{c}\text { Large particles } \\
\text { volume fraction }\end{array}$ & $Q$ \\
\hline CS & $55 \%$ & & $\infty$ \\
CM & $30 \%$ & $30 \%$ & 3.12 \\
CL & & $55 \%$ & 0 \\
\hline
\end{tabular}

Table 1 details the content of the polyacrylate/glass beads composites used. In this table, the ratio $Q$ is introduced. It is defined as $\frac{\text { surface of small particles }}{\text { surface of large particles }}$. This ratio informs on the surfaces available for filler/matrix adhesion for both kinds of particles. The particles volume fractions $f$ and the particles specific surfaces $s$ of 
both the large and the small particles are used to calculate $Q$ :

$$
Q=\frac{f_{\text {smallparticles }}}{f_{\text {largeparticles }}} \times \frac{s_{\text {smallparticles }}}{s_{\text {largeparticles }}}
$$

\subsubsection{Propellants}

Two kinds of energetic networks were used. Matrix A is a plasticized poly(diethylene glycol) adipate and matrix B is a plasticized glycidyl azide polymer. They were filled with $50 \%$ volume fraction of either ammonium perchlorate or HMX particles. For both types of particles, the small particles size distribution lies in the range 2-10 $\mu \mathrm{m}$ and the large particles size distribution in the range 20-100 $\mu \mathrm{m}$. These size distributions are similar to those commonly used in industrial applications $[3,9,14,26]$. Figure 3 presents the shapes of the energetic fillers introduced. The overall shapes of the two kinds of fillers are similar except that the HMX particles have slightly sharper angles.

(a)

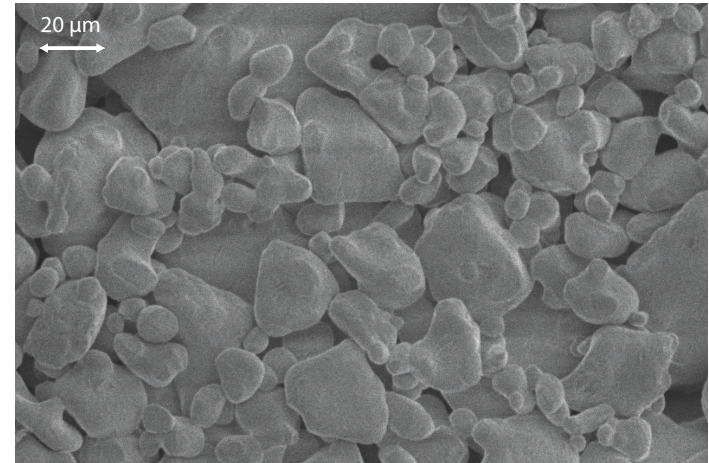

(b)

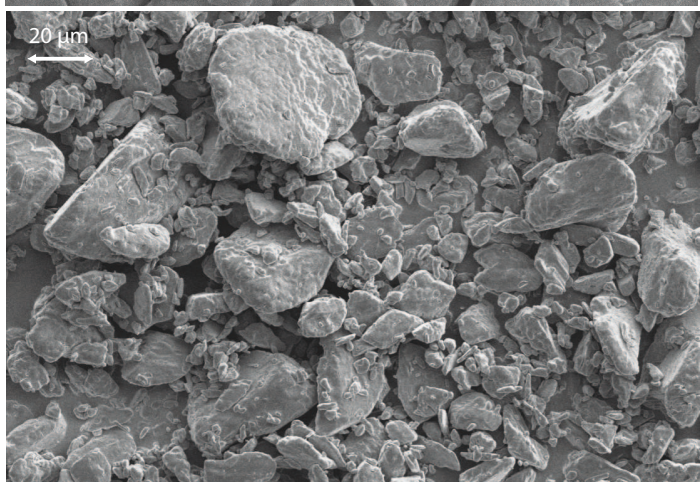

Fig. 3 Shape of the energetic fillers (a) ammonium perchlorate (b) HMX.

Table 2 describes the propellant materials used and their contents. Composites with matrix B and ammonium perchlorate were not produced because even a low friction was liable to ignite them. The values of the $Q$ ratio for each propellant materials are detailed. One should notice that comparable $Q$ ratio values are used, including for the polyacrylate/glass beads composites described in section 2.1.1. 
Table 2 Content of the propellants used in the present study. AP stands for ammonium perchlorate. Proportions of particles are volume fractions.

\begin{tabular}{llllll}
\hline Name & Matrix & Particles & $\begin{array}{c}\text { Small } \\
\text { particles }\end{array}$ & $\begin{array}{c}\text { Large } \\
\text { particles }\end{array}$ & $Q$ \\
\hline APS & A & AP & $50 \%$ & & $\infty$ \\
APM1 & A & AP & $12 \%$ & $38 \%$ & 1 \\
APM2 & A & AP & $25 \%$ & $25 \%$ & 3.18 \\
APL & A & AP & & $50 \%$ & 0 \\
\hline AHS & A & HMX & $50 \%$ & & $\infty$ \\
AHM1 & A & HMX & $16.6 \%$ & $33.3 \%$ & 1.54 \\
AHM2 & A & HMX & $25 \%$ & $25 \%$ & 3.18 \\
AHL & A & HMX & & $50 \%$ & 0 \\
\hline BS & B & HMX & $50 \%$ & & $\infty$ \\
BM & B & HMX & $16.6 \%$ & $33.3 \%$ & 1.54 \\
BL & B & HMX & & $50 \%$ & 0 \\
\hline
\end{tabular}

\subsection{Testing devices}

The mechanical behaviors of the polyacrylate/glass beads composites were characterized in uniaxial tension on an Instron 5881 testing machine equipped with a $1 \mathrm{kN}$ load cell. The true strain was measured by video extensometry. Dogbone samples with a $20 \times 4 \times 4 \mathrm{~mm}^{3}$ working zone were tested. The crosshead speed was chosen at $1 \mathrm{~mm} \cdot \mathrm{min}^{-1}$ to limit viscous dissipation. The mechanical behavior of propellant was tested on dogbone samples with a $40 \times 10 \times 5 \mathrm{~mm}^{3}$ working zone on a Zwick Z1 machine equipped with a $1 \mathrm{kN}$ load cell and supporting video extensometry. Propellant samples were loaded at a constant crosshead speed of $5 \mathrm{~mm} \cdot \mathrm{min}^{-1}$. For each material, at least four samples were tested and since good reproducibility was obtained only the median behavior and extreme failure properties are represented.

A gas dilatometer was installed on an Instron 4204 machine to record sample volume changes through uniaxial tensile tests. A 10 mbar NicheSensor pressure sensor and a $2 \mathrm{kN}$ Zwick load cell were used. This device has been developed for highly filled composites with incompressible constituents to follow the appearance of inner porosity inside the material [7]. It was used for parameter studies and model validation $[31,18]$. A modified dogbone sample was introduced into a hermetically closed chamber and loaded in uniaxial tension. Throughout the test, the pressure of the fluid (air) filling the chamber was recorded. Boyle-Mariotte thermodynamic law was applied to access the volume variation from these pressure measurements. A $0.1 \%$ sensitivity was achieved by combining three procedures: (i) optimal reduction of the initial volume of air filling the chamber in order to increase the pressure variation caused by inner porosity creation, (ii) use of large samples, with a $55 \times 7 \times 7 \mathrm{~mm}^{3}$ working zone to maximize the created volumes and (iii) the loading velocity set at $23.33 \mathrm{~mm} . \mathrm{min}^{-1}$ (resp. $50 \mathrm{~mm} . \mathrm{min}^{-1}$ ) for the polyacrylate/glass beads composites (resp. for the propellants).

Observations of the microstructure in tension were performed into a microtomograph. Samples of polyacrylate/glass beads composites were loaded in uniaxial tension up to $15 \%$ strain at a crosshead speed of $1 \mathrm{~mm} \cdot \mathrm{min}^{-1}$. In order to maintain 
the state of strain, rigid glassy polymers strips were glued on two opposite sides of the strained samples with a loctite glue. A length of $15 \mathrm{~mm}$ of the obtained sandwich structures working length were then imaged by X-ray tomography at Laboratoire NAVIER, Ecole des Ponts ParisTech with a UltraTom device from RX-Solutions (Chavanod, France). Source parameters were $73 \mathrm{kV}$ and $70 \mu \mathrm{A}$. $5 \mu \mathrm{m}$ large voxels were obtained. Each global scan required approximately two hours and 1440 projections during a specimen rotation of $360^{\circ}$. Reconstruction was performed with the algorithm implemented by the manufacturer of the microtomograph into 16-bit images.

\section{Mechanical behavior}

Figure 4 illustrates the stress-strain behavior in uniaxial tension of the polyacrylate matrix filled with various ratios of large and small particles. Two stages appear: first an increase in stress, second a sharp stress softening that leads to a stress plateau in the case of CM and CS. The initial slope of the stress/strain curve is seemingly unaffected by the particles size distribution. This effect has been documented earlier [8]. Composites CL and CS on the one hand and composite CM on the other hand have slightly different filler fractions and should thus display differences in the initial slopes of their stress/strain curve. However, the three materials experience an early softening of their stress/strain curves, which hides the difference in initial slopes.

The stress at which sharp stress softening begins depends on the fraction of small particles: the higher the small particles volume fraction, the higher the stress value at which sharp stress softening begins. As regards the failure properties, one notices that adding small particles has a beneficial effect on the stress at break but no significant effect on the strain at break. For this kind of composites, the material containing a mix of small and large particles displays an intermediate mechanical behavior that stands between large particles and the small particles composites.

Figure 5a (resp. 5b) illustrates the mechanical behavior of propellants matrix A filled with ammonium perchlorate (resp. HMX) particles. As in the case of polyacrylate/glass beads composites, the initial slope of the stress-strain curve is independent of the particles size distribution. Afterwards, the mechanical behavior reaches a plateau stress in the case of ammonium perchlorate. The plateau stress value depends on the size distribution and is enhanced by the presence of small particles. Regarding failure properties, both stress and strain at break are markedly improved by the addition of small particles.

Two distinct mechanical behaviors are obtained in the case of HMX. The first group contains AHS only and displays the highest values of stress. The second group is constituted by AHL, AHM1 and AHM2, which display very similar mechanical behaviors. One notes also that all four stress-strain curves display an upturn, which is not present for ammonium perchlorate filled materials. Thus, propellants with matrix A display two distinct effects of the mix of large and small particles: (i) In the case of ammonium perchlorate fillers, APM1 and APM2 composites display a mechanical behavior that is intermediary between APL and APS composites stress-strain curves, which is consistent with what has been observed on polyacrylate/glass beads composites. (ii) In the case of HMX fillers, AHM1 and 


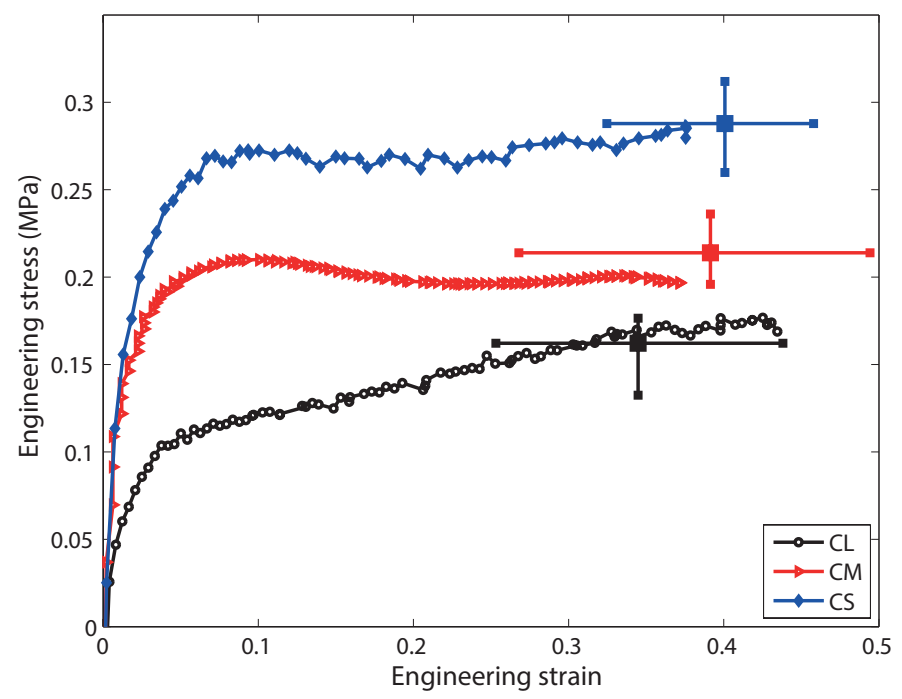

Fig. 4 Stress-strain behavior in uniaxial tension of polyacrylate elastomers filled with a mix of large and small particles.

AHM2 composites behaves as the AHL composite, which suggests that the large particles govern the mechanical behavior notwithstanding the amount of small particles. Previous experimental results on explosives [6] feature polydisperse materials that have different behaviors from corresponding monodisperse materials, being consistent with case (i). However, to the authors knowledge, case (ii) has never been documented so far. Note also that like in the case of ammonium perchlorate, adding small particles of HMX to matrix A has a significant effect on the failure stress.

Nanoindentation experiments on RDX (an energetic organic filler similar to HMX) [12] and ammonium perchlorate [17] have shown that the Young modulus of the particles introduced into the produced composites is a hundred to a thousand times higher than the Young modulus of the binder. Since no particle fracture during low strain-rate experiments has ever been documented on the studied composites, it can be considered that the particles are rigid solids and only differ by their shapes and their adhesions to the binder. Since it has been illustrated in figures $3 \mathrm{a}$ and $3 \mathrm{~b}$ that the considered energetic fillers have very similar shapes, the difference of matrix/filler adhesion is probably responsible for the observed changes on the composite behaviors. This assumption is also supported by previous works on the effect of matrix/filler adhesion on the mechanical behavior of particulates composites [5] and solid propellants [11, 14] arguing that the highest stress levels experienced by ammonium perchlorate filled composites compared to HMX filled composites are due to a better matrix/filler adhesion in the former case.

Figure 5c shows the mechanical behavior of matrix B filled with HMX particles. The three composites display a similar initial behavior. Afterwards, their stress/strain curves diverge, the BL composite constituting a lower bound and the BS composite an upper bound. As for the BM composite, it has a behavior 
(a)

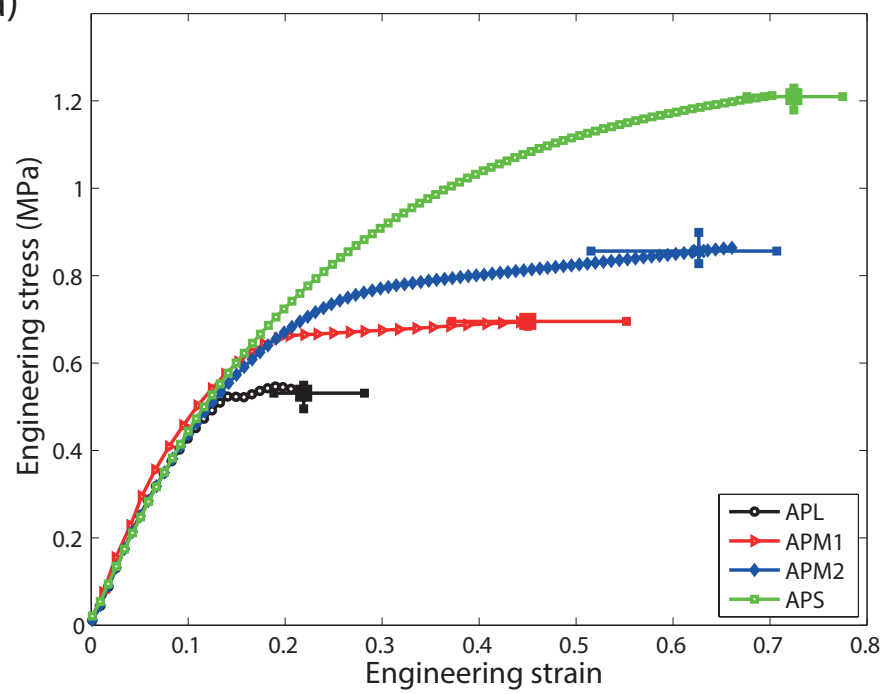

(b)

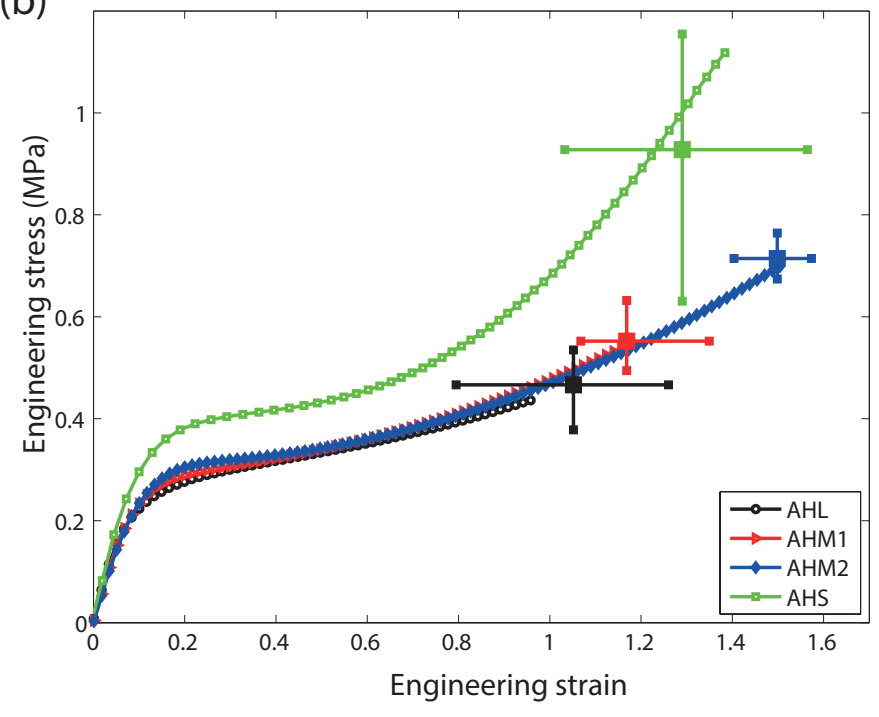

(c)

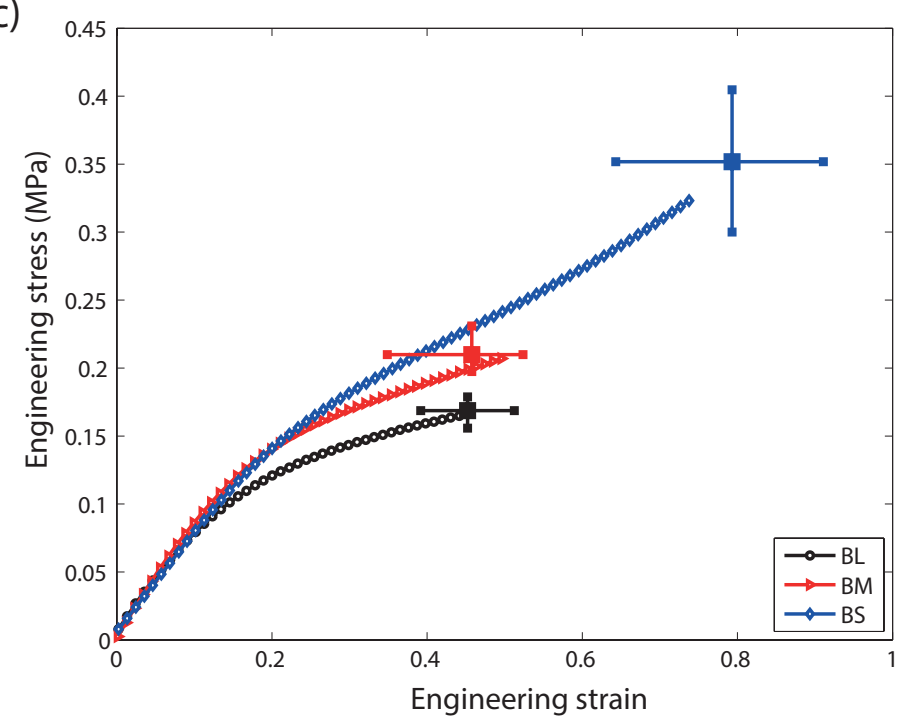

Fig. 5 Uniaxial tension stress-strain behavior of propellants containing different matrices and particles. (a) Matrix A filled with ammonium perchlorate, (b) matrix A filled with HMX, and (c) matrix B with HMX. 
laying between BL and BS. The evolution of BM compared to BL and BS is thus similar to the effect of adding small particles in matrix A filled with ammonium perchlorate. The stress at break is noticeably improved by adding small particles.

Comparing the content of the composites presented in figure $5 \mathrm{~b}$ and $5 \mathrm{c}$, one notes that they only differ by their matrix behavior and matrix/filler adhesion. However, the effect of polydispersity on the mechanical behavior of these composites sharply contrasts. The comparison of the behavior of the polymer matrices in figure 6 shows that the polyacrylate matrix displays higher stress levels than matrix A and suggests that the matrix filler/adhesion in the polyacrylate/glass beads composites is lower than for propellants A since the polyacrylate/glass beads composites experience lower stress levels than the AP propellants.

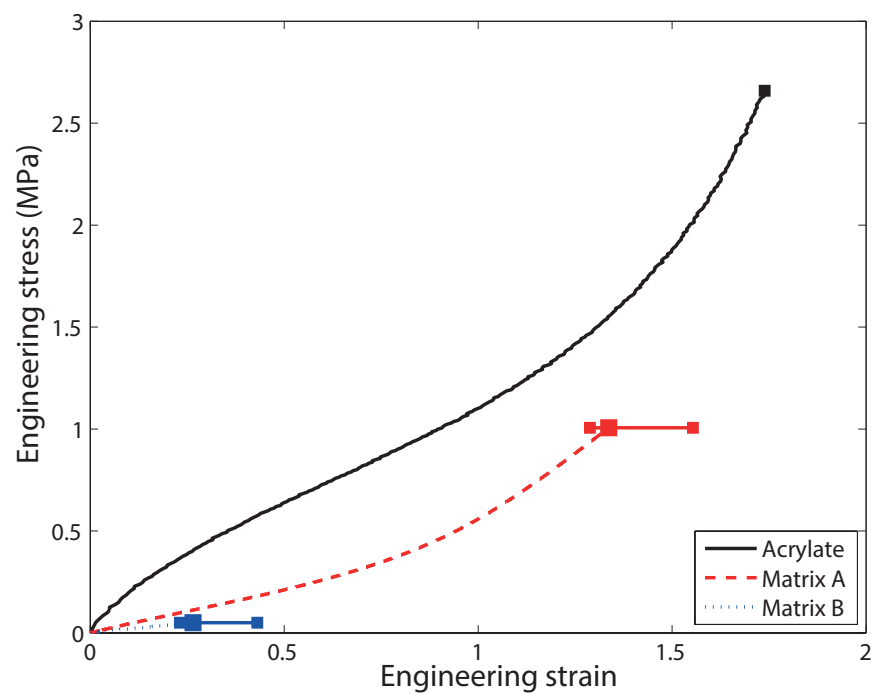

Fig. 6 Uniaxial tension stress-strain behaviors of the different matrices at the strain rate used for the corresponding composites: (a) polyacrylate, (b) matrix A, and (c) matrix B.

\section{Observations of local damage}

\subsection{Volume changes upon stretching}

The evolution of inner porosity during the tension of polyacrylate/glass composites is reported in figure 7. For both tested materials, the inner volume variation displays a non-zero initial slope followed by a quasi linear evolution that leads to a maximum followed by a decrease of the inner porosity. Both the fillers and the matrix are quasi-incompressible materials, therefore debonding and inner cracks are responsible for the increase of the samples inner porosity. When a crack emerges from the sample, the inner voids that were linked by this crack constitute new volumes to be filled by the air in the chamber. Thus the measured pressure decreases, 


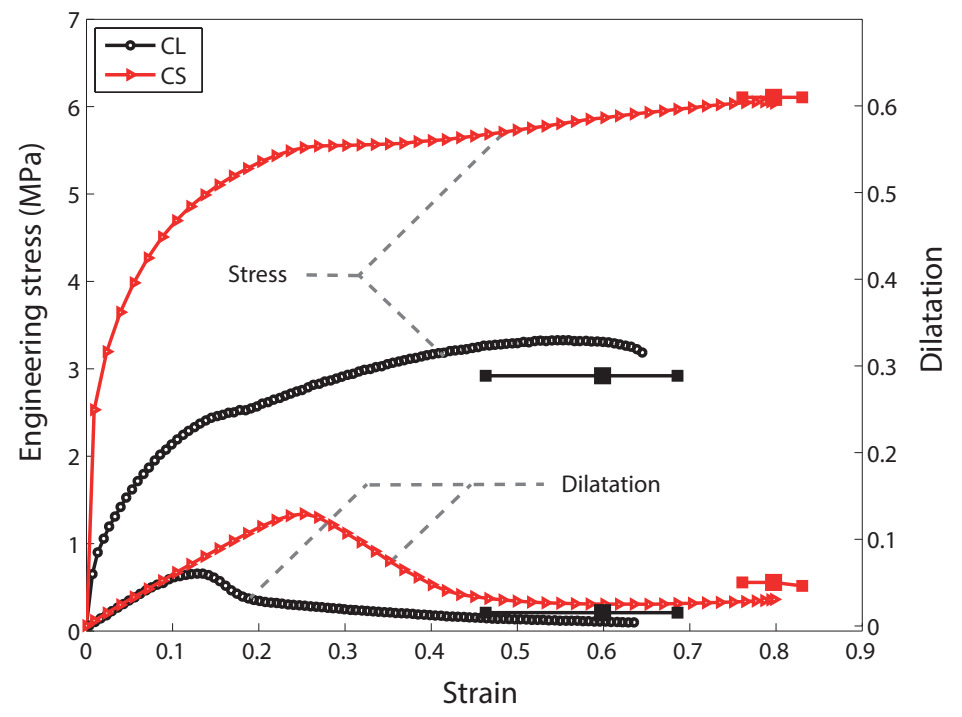

Fig. 7 Stress-strain curve and dilatation behavior in uniaxial tension measured with a gas dilatometer for polyacrylate/glass beads composites with either large or small particles.

which translates into an apparent reduction of the recorded samples volume. It follows that a positive gradient in the dilatation curve means that the quantity of created inner voids is larger than the quantity of voids connected to the chamber air by emerging cracks. For these reasons, the dilatation peak observed in figure 7 assesses the advent of emerging crack becoming prominent compared to the creation of inner voids. For large particles this point of prominent cracking is reached at approximately 0.1 strain, whereas it is obtained at 0.25 strain for small particles. Compared to the failure strain of 0.6 and 0.8 for CL and CS respectively, one notes that the appearance of significant cracks occurs early. One also notices that the appearance of cracks is related to the particles size distribution with the large particles fostering the cracking process. Relating the inner volume variations and the stress-strain curves in figure 7 , one notes that the peak in inner porosity is reached at the same strain as the onset of the plateau-like stress evolution. As expected, when early prominent cracks occur, they govern the mechanical behavior of the composite.

The inner porosity evolution of the various propellants during stretching is illustrated in figure 8. Regarding composites presented in figures $8 \mathrm{a}$ and $8 \mathrm{~b}$, one recognizes an initial dilatation slope of zero and a stage of zero dilatation evolution followed by an increase of the inner porosity. The inner volume change increases with the strain and with the amount of large fillers. Afterwards, two distinct evolutions appear depending on the particles nature. For ammonium perchlorate in figure 8a, a maximum in the dilatation curve is observed, after which the inner volume slope decreases, for APL and APM1 composites. These two composites contain high ratios of large particles. This evolution is similar to what has been observed in polyacrylate/glass beads composites and characterizes the appearance of cracks in the microstructure. For composites filled mainly with small particles 
(a)

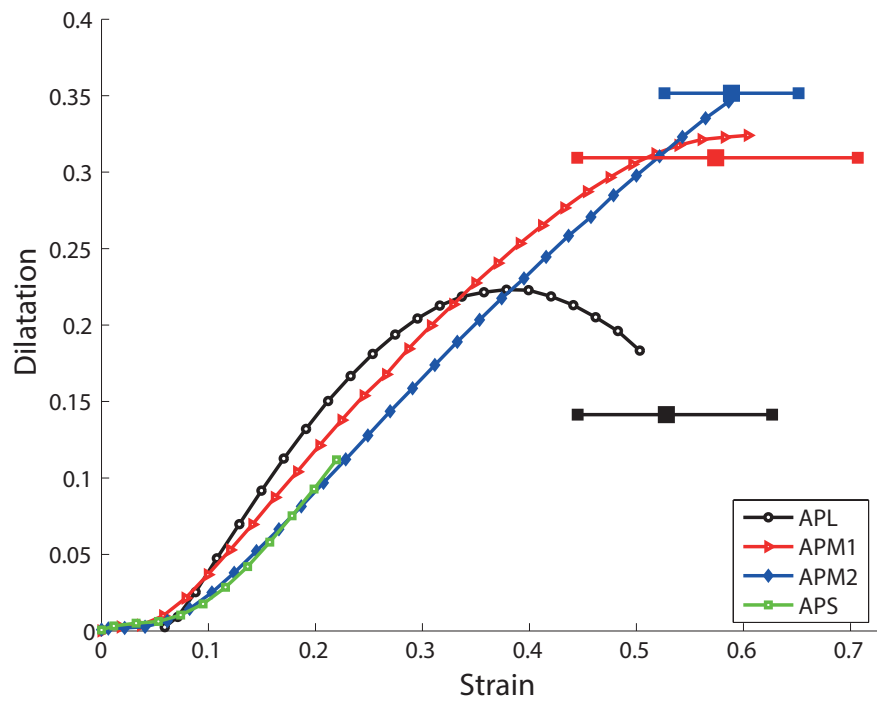

(b)

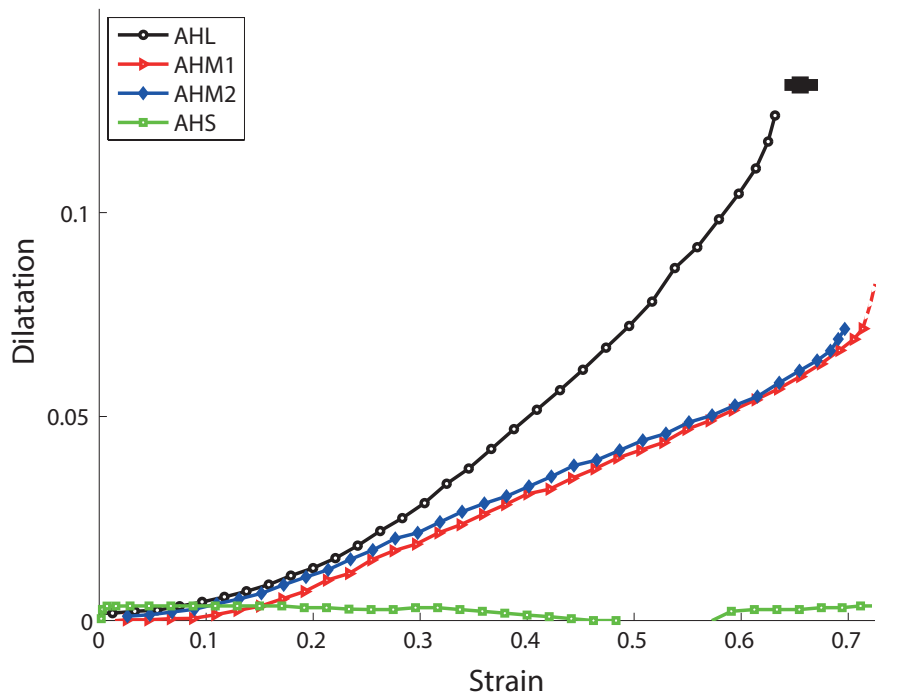

(c)

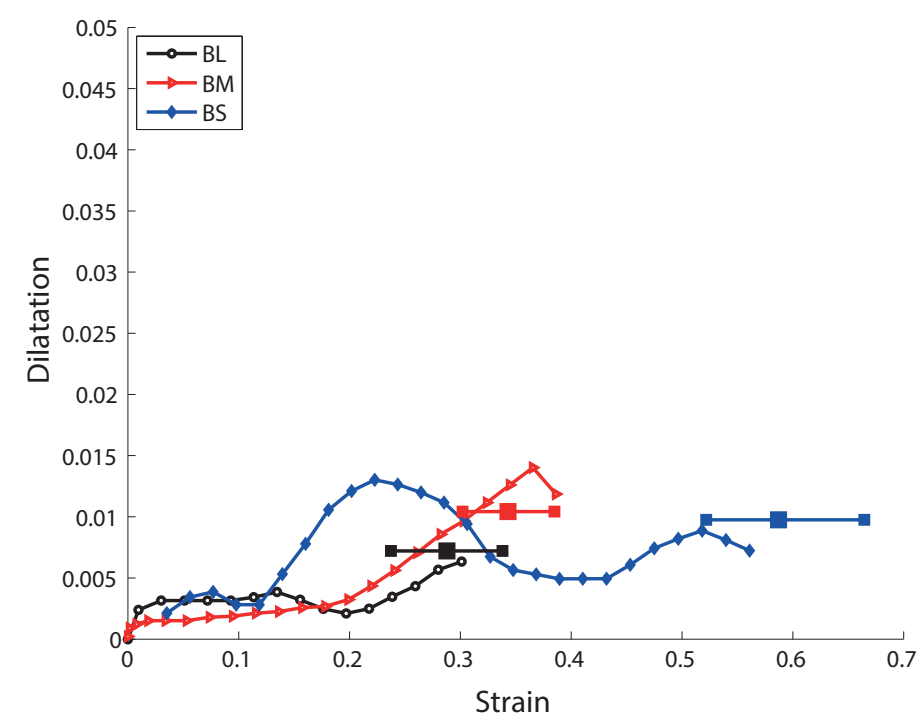

Fig. 8 Specimen dilatation upon uniaxial tension for: a) propellants with matrix A filled with ammonium perchlorate, b) propellants with matrix A filled with HMX and c) propellants with matrix B filled with HMX. In the case where rupture markers are not plotted, the test settings did not allow to reach material failure, either because applicable displacement was too small (matrix A filled with small particles of HMX) or because failure occurred in the samples head (matrix A filled with small particles of ammonium perchlorate). 
and for HMX filled composites (figure 8b), the raise of inner volume is pursued until failure. One also notices that the inner volume values reached for matrix A filled with ammonium perchlorate are two to three times higher than the ones for matrix A filled with HMX. Before emerging from the samples, cracks are liable to create cavities that encompass the existing voids created by debonding and extra voids stemming from matrix breakage and local deformations. Therefore, this gap in volumes of inner porosities supports the fact that distinct damaging mechanisms prevail in these two composites: debonding predominates for low inner volume values, whereas significant cracks finally emerging on the surface of the samples predominate for large ones.

Figure $8 \mathrm{c}$ illustrates the inner volume evolution of matrix B filled with HMX. It appears that the performance of the measurement device was not sufficient to record a meaningful signal. This means that the maximum inner porosity variation is around $1 \%$ in these composites. This also suggests that final break is reached as soon as one crack forms for propellants with matrix B, thus explaining their early failure. This observations is consistent with the very low failure properties of matrix B.

The features of the inner porosity variations can be related to the trends highlighted on the mechanical behavior of the composites in section 3. Indeed, it appears that polydisperse composites yielding behaviors intermediary between large only and small only particles composites also display early prominent cracks, whereas cracks do not prevail in polydisperse composites having a mechanical behavior very similar to the corresponding large particles only materials.

\subsection{Microtomography observation}

Microtomography slices of of polyacrylate composites with large particles and small particles only strained at $15 \%$ are shown in figures 9 and 10 . According to figure 7 , the large particles polyacrylate composite should present noticeable cracks while the small particles polyacrylate composite may not. Comparing figures 9a for a pristine microstructure and figure $9 \mathrm{~b}$ for $15 \%$ strain, one notices two damaging mechanisms: matrix/particle debonding, which is a well-known feature of highly filled elastomers $[10,26,20,1]$ and large cracks. Two cracks extending on several particles lengths can indeed be observed in figure $9 \mathrm{~b}$. The debonding around other particles suggests that cracks appear after coalescence of voids formed by particle/matrix debonding. Although significant cracks have appeared at $15 \%$ strain, figure 4 shows that sample failure occurs at a much larger strain (35\%). Therefore, the presence of cracks does not lead to immediate failure of the specimen. One also recognizes that the failure process creates large amounts of inner porosities in the material. This observation extends to the dilatation results in figure $8 \mathrm{a}$ and $8 \mathrm{~b}$, where propellants displaying cracks also experienced the highest values of volume changes.

Such a damaging process has already been reported in explosives loaded in compression [25]. For propellants, crack growth and its effect on the mechanical behavior of the bulk material have been extensively studied with fracture mechanics approaches $[16,19,21,30]$. Moreover, the influence of such phenomena as aging [13] or particle size and treatment [5] on the cracking process has been established. However, fracture mechanics approaches concentrate on the propaga- 
(a)

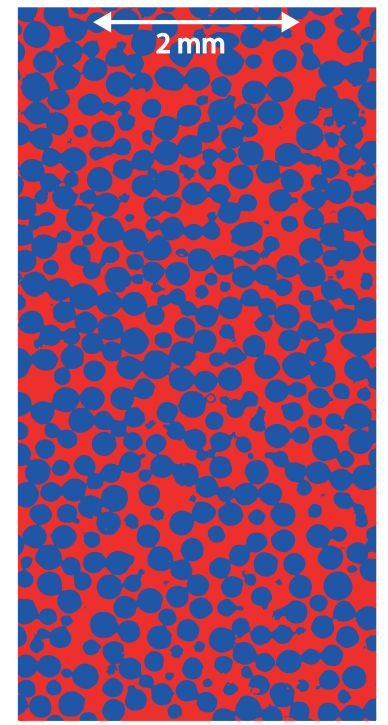

(b)

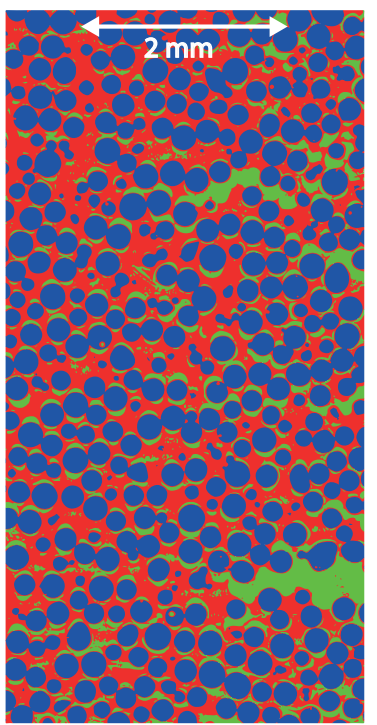

Fig. 9 Thresholded tomographic slices through specimens of polyacrylate/glass beads composite filled with large particles only at: a) 0 macroscopic strain and b) $15 \%$ macroscopic strain. The loading direction is vertical.

tion of a pre-existing crack at the macroscale. For this reason, the early advent of cracks demonstrated here is a new feature that should be taken into account when studying damage evolution in highly filled elastomers.

Figure 10 illustrates a tomographic slice on a small particles composite for the same strain of $15 \%$. One recognizes, either on an image obtained with the tomograph settings described in section 2.2 (figure 10a) or on an enlarged view (figure 10b), that no large crack is observed but only distributed particle/matrix debonding. Thus, at the applied strain, a strong difference is highlighted between composites containing either large or small particles: cracks have developed in the presence of large particles, while matrix/filler debonding prevails when only small particles are present. This corroborates the interpretation of the gas dilatometer results, according to which not only matrix/filler debonding but also early cracks are responsible for the particle size effect in highly filled elastomers.

\section{Conclusion}

A polyacrylate elastomer and two propellant binders have been highly filled with different size distributions of particles of different chemical natures. The mechanical behavior of these composites in uniaxial tension has been assessed and revealed two distinct possible impacts of the presence of small particles depending on the matrix/particles adhesion and on the matrix behavior. Adding small particles to elastomers highly filled with micrometric particles could thus either yield mechanical behaviors that are intermediary between the large particle composites and the 


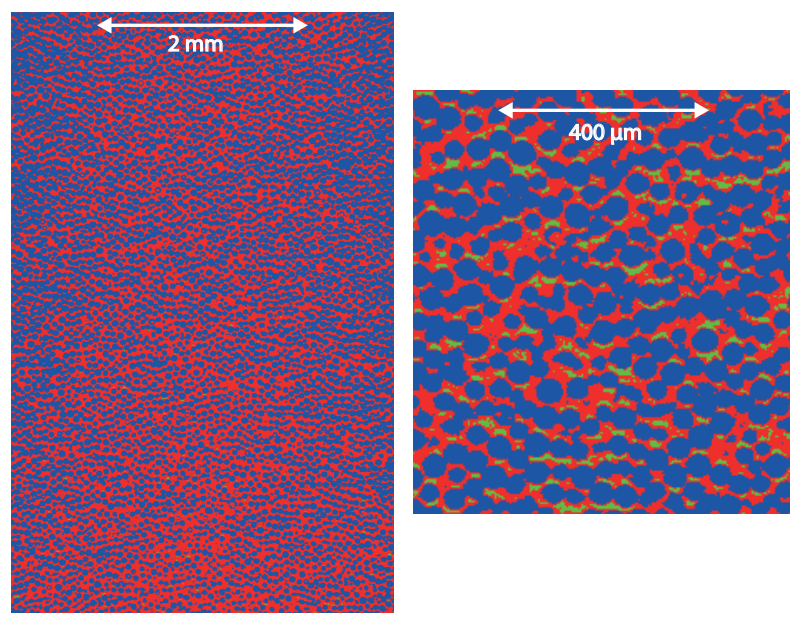

Fig. 10 Thresholded tomographic slice through a specimen of polyacrylate/glass beads composites filled with small particles only at 0.15 macroscopic strain. The loading direction is vertical. (a) Image obtained with the tomograph settings presented in section 2.2 and (b) enlarged view.

small particle composites, or behaviors similar to the large particle composites. The evolutions of the inner volume of the tested composites have been recorded throughout the uniaxial tension tests. Results have unveiled the appearance of cracks at an early strain compared to the failure strain in the case where the polydisperse composites display intermediary mechanical behaviors. This suggests that the influence of particles polydispersity on the stress-strain curve is related to the advent of early cracks in the material. Therefore, adding small particles delay the appearance of early prevailing cracks and improves the mechanical behavior of composites where these cracks advent. When no early crack appears, the mechanical behavior of polydisperse composites is governed by the presence of large particles.

\section{Acknowledgements}

Mr P.-A. Toulemonde thanks DGA for its financial support. The authors gratefully acknowledge the help of Dr Patrick Aimedieu from Laboratoire Navier for experiments with microtomography. This device has been funded by the Île de France region with the SESAME 2007 program. The authors would also like to acknowledge the help of Adrien Leneindre from Herakles groupe Safran for implementing the gas dilatometer device. 


\section{References}

\section{References}

1. Bencher, C.D., Dauskardt, R.H., Ritchie, R.O.: Microstructural damage and fracture processes in a composite solid rocket propellant. Journal of Spacecraft and Rocket 32, 328-334 (1995)

2. Cho, J., Joshi, M.S., Sun, C.T.: Effect of inclusion size on the mechanical properties of polymeric composites with micro and nano particles. Composite Science and Technology 66, 1941-1952 (2006)

3. Cornwell, L.R., Schapery, R.A.: SEM study of microcracking in strained solid propellant. Metallography 8, 445-452 (1975)

4. Davenas, A.: Technologie des Propergols Solides. Masson (1988)

5. Dreyfuss, P., Gent, A.N., Williams, J.R.: Tear strength of model filled elastomers. Journal of Polymer Science 18, 2135-2142 (1980)

6. Drodge, D.R., Williamson, D.M.: Understanding damage in polymer-bonded explosive composites. Journal of Materials Science 51, 668-679 (2016)

7. Farris, R.J.: Dilatation of granular filled elastomers under high rates of strain. Journal of Applied Polymer Science 8, 25-35 (1964)

8. Fu, S.Y., Feng, X.Q., Lauke, B., Mai, Y.W.: Effects of particle size, particle/matrix interface adhesion and particle loading on mechanical properties of particulate-polymer composites. Composites: Part B 39, 933-961 (2008)

9. Gallier, S., Hiernard, F.: Microstructure of composite propellants using simulated packings and X-ray tomography. Journal of Engineering Materials and Technology 114, 111-115 (2008)

10. Gent, A.N., Park, B.: Failure processes in elastomers at or near a rigid spherical inclusion. Journal of Materials Science 19, 1947-1956 (1984)

11. Hori, K., Iwama, A., Fukuda, T.: On the adhesion between hydroxy-terminated polybutadiene fuel-binder and ammonium perchlorate. Performance of bonding agents. Propellants, Explosives and Pyrotechnics 10, 176-180 (1985)

12. Hudson, R.J., Zioupos, P., Gill, P.P.: Investigating the mechanical properties of RDX crystals using nano-indentation. Propellants, Explosives and Pyrotechnics 37, 191-197 (2012)

13. Ide, K.M., Ho, S.Y.: Fracture behaviour of accelerated aged solid rocket propellants. Journal of Materials Science 34, 4209-4218 (1999)

14. Kim, C.S., Noble, P.N., Zoun, C.H., Tarrant, D., Gao, A.: The mechanism of filler reinforcement from addition of neutral polymeric bonding agents to energetic polar propellants. Propellants, Explosives, Pyrotechnics 17, 51-58 (1992)

15. Landsem, E., Jensen, T.L., Hansen, F.K., Unneberg, E., Kristensen, T.E.: Neutral polymeric bonding agents (NPBA) and their use in smokeless composite rocket propellants based on HMX-GAP-BuENA. Propellants, Explosives, Pyrotechnics 37, 581-591 (2012)

16. Liu, C.T., Nevière, R., Ravichandran, G.: Crack growth behavior in a highly filled elastomer. In: Proceedings of the 16th European Conference of Fracture. Springer, Alexandroupolis (2006)

17. Lucca, D.A., Klopfstein, M.J., Mejia, O.R., Rossettini, L., De Luca, L.T.: Investigation of ammonium perchlorate by nanoindentation. Materials Science and Technology 22, 396-401 (2006) 
18. Nevière, R.: An extension of the time-temperature superposition principle to non-linear viscoelastic solids. International Journal of Solids and Structures 43, 5295-5306 (2006)

19. Nottin, J.P., Gondouin, B., Lucas, M.: Experimental investigation of cracks growth in composite propellants. AIAA, California (1985)

20. Oberth, A.E., Bruenner, R.S.: Tear phenomena around solid inclusions in castable elastomers. Transaction of the Society of Rheology 9, 577-588 (1965)

21. Rao, S., Krishna, Y., Rao, B.N.: Fracture toughness of nitramine and composite solid propellants. Materials Science and Enginering 403, 125-133 (2005)

22. Renie, J.P., Condon, J.A., Osborn, J.R.: Oxidizer size distribution effects on propellant combustion. AIAA Journal 17, 877-883 (1979)

23. Safranski, D., Gall, K.: Effect of chemical structure and crosslinking density on the thermo-mechanical properties and toughness of (meth)acrylate shape memory polymer networks. Polymer 49, 4446-4555 (2008)

24. Siviour, C.R., Gifford, M.J., Walley, S.M., Proud, W.G., Field, J.E.: Particle size effects on the mechanical properties of a polymer bonded explosive. Journal of Materials Science 39, 1255-1258 (2004)

25. Siviour, C.R., Laity, P.R., Proud, W.G., Field, J.E., Porter, D., Church, P.D., Gould, P., Huntingdon-Thresher, W.: High strain rate properties of a polymerbonded sugar: their dependence on applied and internal constraints. Proceedings of the Royal Society 464, 1229-1255 (2008)

26. Tao, Z.J., Ping, S.D., Mei, Z., Cheng, Z.P.: Microstructure deformation and fracture mechanism of highly filled polymer composites under large tensile deformation. In: 12th International Symposium on Multiscale, Multifunctional and Functionaly Graded Materials. IOP Science (2013)

27. Thomas, D.G.: Transport characteristics of suspension. VIII A note on the viscosity of newtonian suspensions of uniform spherical particles. Journal of Colloid Science 20, 267-277 (1965)

28. Toulemonde, P.A., Diani, J., Gilormini, P., Desgardin, N.: On the account of a cohesive interface for modeling the behaviour until break of highly filled elastomers. Mechanics of Materials 93, 124-133 (2016)

29. Toulemonde, P.A., Diani, J., Gilormini, P., Lacoirx, G., Desgardin, N.: Roles of the interphase stiffness and percolation on the behaviour of solid propellants. Propellants, Explosives and Pyrotechnics (2017). In press

30. Tussiwand, G.S., Saouma, V.E., Terzenbach, R., De Luca, L.T.: Fracture mechanics of composite solid rocket propellant grains: material testing. Journal of Propulsion and Power 25, 60-73 (2009)

31. Vratsanos, L.A., Farris, R.J.: A predictive model for the mechanical behavior of particulate composites. Part II: comparison of model to literature data. Polymer Engineering and Science 33, 1466-1474 (1993) 